\title{
PENGARUH FOTOOKSIDASI UV-C TERHADAP SIFAT FISIKOKIMIA DAN BAKING EXPANSION PATI SAGU (Metroxylon sago)
}

\author{
Eduard Fransisco Tethool*, Angela Myrra Puspita Dewi, Abadi Jading \\ Jurusan Teknologi Pertanian, Fakultas Teknologi Pertanian, Universitas Papua \\ Email: e.tethool@unipa.ac.id
}

\begin{abstract}
Native Sago starch is difficult to be used in industry because of the limitations of its properties. The aim of this research was to study effect of UV-C photo-oxidation on chemical properties and baking expansion of sago starch. Five slurry ratio (starch : water ratio): 1:2; 1:4; $1: 6 ; 1: 8$; and 1:10 were oxidized with UV-C irradiation for 20 minutes, and then compared with native sago starch. The results showed that UV-C photooxidation increased amylose content and paste viscosity, but decreased swelling power and solubility, and carbonyl and carboxyl content. Used of UV-C as a photooxidator was effective in increasing baking expansion characteristic, and the best slurry ratio was 1:6, which has $6.97 \mathrm{ml} / \mathrm{g}$ specific volume or $33.7 \%$ higher than that of native sago starch $(5.22 \mathrm{ml} / \mathrm{g})$
\end{abstract}

Keywords: sago, photo-oxidation, uv-c, baking expansion

\section{PENDAHULUAN}

Sagu (Metroxylon sago) merupakan salah satu sumber bahan pangan di beberapa daerah di Indonesia seperti Maluku, Papua, Mentawai, dan Sulawesi (Haryanto dan Pangloli, 1991). Flach (1997) menyebutkan bahwa dari 2,2 juta ha lahan sagu yang ada di seluruh dunia, sekitar 1,4 juta ha terdapat di hutan-hutan Indonesia dan sekitar 0,994 juta areal sagu terdapat di Papua. Salah satu sentra produksi sagu di Papua adalah daerah Sentani. Khusus di daerah sentani saja, tedapat sekitar 20 kultivar sagu. Dari sekian banyak kultivar tersebut yang paling sering dikonsumsi oleh masyarakat Sentani adalah kultivar Para, Yepha, Ruruna dan Rondo. Hal ini disebabkan karena keempat kultivar ini memiliki produktivitas dan citarasanya yang lebih yang lebih baik dibandingkan kultivar lainnya (Limbongan, 2007). Dari keempat kultivar tersebut, kultivar Ruruna memiliki sifat pengembangan pati yang paling baik (Tethool et al., 2009).

Meskipun memiliki potensi sagu yang besar, pemanfaatan pati sagu khususnya di Papua masih terbatas sebagai bahan makanan tradisional, dengan konsumsi terbatas pada masyarakat lokal asli Papua. Pemanfaatan sagu dalam industri pangan yang lebih luas masih terbatas, karena sifat fisikokimia yang dimiliki. Tethool et al. (2009) melaporkan bahwa pati sagu varietas unggul memiliki kandungan amilosa yang tinggi sehingga daya pengembangannya menjadi terbatas. Padahal sifat pengembangan ini dibutuhkan oleh berbagai industri pangan lainnya seperti industri mi dan bakery.

Guna memperbaiki sifat pengembangan ini maka salah satu cara yang dapat dilakukan adalah dengan modifikasi kimia berupa oksidasi. Oksidasi pati banyak digunakan karena menghasilkan pati yang memiliki viskositas rendah, stabilitas pasta tinggi, kejernihan pasta tinggi, serta memiliki daya pengembangan dan sifat perekat yang baik (Sanchez-Rivera et al. 2005). Selama proses oksidasi, gugus hidroksil pada molekul pati akan teroksidasi menjadi gugus karboksil dan karbonil. Reaksi oksidasi juga mengakibatkan terjadinya degradasi molekul pati sehingga viskositas pasta rendah. Metode oksidasi yang dapat digunakan antara lain dengan reagen kimia atau fotooksidasi dengan ultra violet.

Penelitian ini bertujuan untuk mengetahui pengaruh fotooksidasi Ultraviolet tipe C (UV-C) terhadap sifat fisikokimia dan sifat baking expansion pati sagu, sehingga dapat dijadikan informasi dasar untuk 
pengembangan potensi pemanfaatan pati sagu.

\section{BAHAN DAN METODE}

\section{Bahan dan Alat}

Bahan yang digunakan dalam penelitian antara lain: pati sagu asal Wasior Papua Barat, aquades, $\mathrm{NaOH}, \mathrm{HCl}$, Hydroxilamine, amilosa standar serta bahan kimia lain untuk analisa, keseluruhannya dalam grade untuk analisa (PA) Sigma. Peralatan yang digunakan: alat reaktor oksidasi yang dilengkapi dengan lampu UVC, oven (UNB-400); chromameter (Konica Minolta CR-400); spectrophotometer (Shimadzu UV mini 1240), serta alat gelas dan peralatan analisa lainnya.

\section{Metode Pengujian}

Fotooksidasi Pati

Fotooksidasi dilakukan dengan menggunakan reaktor oksidasi yang dilengkapi lampu UV-C untuk reaksi fotooksidasi, tangki bahan berbahan stainless steel, pompa air, dan motor pengaduk seperti ditampilkan pada Gambar 1. Bahan yang berupa slurry pati dengan rasio tertentu dimasukkan dalam tangki bahan kemudian slurry pati dialirkan melewati lampu UV-C secara kontinu, untuk mencegah terbentuknya endapan pati maka slurry pati dilakukan pengadukan.

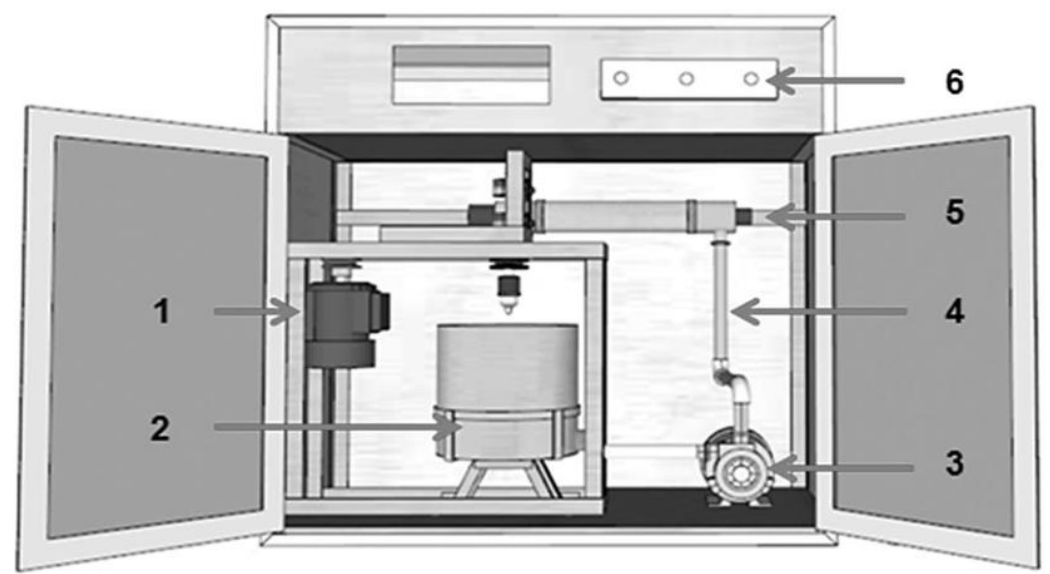

Keterangan :

1. Motor Pengaduk

4. Pipa Sirkulasi

2. Tanki Bahan (Slurry Pati)

5. Lampu UV-C (Tanki Fotoreaktor)

3. Pompa Bahan

6. Panel Kontrol

Gambar 1. Skema Alat Fotooksidasi

Perlakuan yang digunakan adalah 5 taraf rasio slurry (perbandingan pati : air), yaitu 1 (pati) : 2 (air); 1:4; 1:6; 1:8; dan 1:10. Slurry pati yang dibuat sesuai perlakuan masing-masing dimasukkan ke dalam tangki bahan, selanjutnya dipompa dan dialirkan ke dalam tabung berisi lampu UV C sebagai fotooksidator, dan kemudian akan kembali lagi ke dalam tangki bahan. Sirkulasi fotooksidasi dilakukan selama 20 menit, dengan laju aliran slurry dipertahankan pada kecepatan $5 \mathrm{gpm}$. Setelah proses fotooksidasi selesai, slurry pati dikeluarkan kemudian dicuci dengan pembilasan air bersih sebanyak 3 kali untuk menghentikan reaksi oksidasi, selanjutnya dilakukan pengendapan. Pati sagu teroksidasi yang diperoleh kemudian dikeringkan pada cabinet dryer dengan suhu $50{ }^{\circ} \mathrm{C}$ selama 18 jam.

\section{Karakteristik Sifat Fisikokimia Pati Sagu}

Pati sagu hasil oksidasi dengan 5 rasio slurry selanjutnya dikarakterisasi sifat fisikokimianya, dengan pati alami sebagai pembanding. Warna pati (derajat putih) diukur 
dengan menggunakan chromameter (Minolta CR-400).

Daya pengembangan dan kelarutan ditentukan dengan metode Adebowale et al. (2002). Pati sebanyak $1 \mathrm{~g}$ dimasukan dalam tabung uji dan ditimbang kembali (W1, g). Sampel kemudian didispersikan dengan ditambahkan air hingga volume $50 \mathrm{ml}$, dipanaskan pada suhu $95{ }^{\circ} \mathrm{C}$ selama 30 menit dalam waterbath. Campuran yang telah tergelatinisasi kemudian didinginkan hingga $30{ }^{\circ} \mathrm{C}$ dan disentrifugasi (500 rpm, 15 menit). Supernatant yang dihasilkan, diambil aliquot $(5 \mathrm{ml})$ lalu dikeringkan pada suhu $110{ }^{\circ} \mathrm{C}$ hingga diperoleh berat konstan. Kelarutan ditentukan berdasarkan residu kering yang dihasilkan. Endapan gel ditimbang bersama wadah tabung (W2) dan ditentukan sebagai daya pengembangan pati.

\section{Daya Pengembangan Pati $=\mathrm{W} 2-\mathrm{W} 1 /$ berat pati}

Kadar amilosa pati ditentukan dengan metode AOAC (2005). Sebanyak $100 \mathrm{mg}$ sampel pati dimasukkan ke dalam tabung reaksi, ditambahkan $1 \mathrm{ml}$ etanol $95 \%$ dan $9 \mathrm{ml}$ $\mathrm{NaOH} 1 \mathrm{~N}$. Campuran dipanaskan selama 10 menit, dipindahkan dalam labu takar $100 \mathrm{ml}$ ditepatkan sampai tanda tera dengan aquades. Larutan tersebut diambil $5 \mathrm{ml}$, dimasukkan dalam labu takar $100 \mathrm{ml}$, ditambahkan $1 \mathrm{ml}$ asam asetat $1 \mathrm{~N}$ dan $2 \mathrm{ml}$ iod $0,2 \%$, ditambahkan aquades sampai tanda tera, lalu dibiarkan 20 menit dan intensitas warna biru ditera dengan spektrofotometer pada $\lambda 625$ nm. Kadar amilosa sampel ditentukan dengan kurva standar menggunakan amilosa murni.

Kadar karbonil ditentukan dengan metode Smith et al. (1986). Sebanyak $2 \mathrm{~g}$ sampel dilarutkan dalam $100 \mathrm{ml}$ aquades, kemudian larutan digelatinisasi pada suhu $100^{\circ} \mathrm{C}$ (20 menit), lalu didinginkan hingga suhu $40^{\circ} \mathrm{C}$. $\mathrm{pH}$ sampel diatur 3,2 dengan penambahan $0,1 \mathrm{~N} \mathrm{HCl}$. Ke dalam sampel ditambahkan $15 \mathrm{ml}$ reagen hydroxylamine, kemudian dipanaskan dalam waterbath pada suhu $40^{\circ} \mathrm{C}$ selama 4 jam. Sisa hydroxylamine ditentukan dengan titrasi menggunakan $0,1 \mathrm{~N}$ $\mathrm{HCl}$.

$$
\text { kadar karbonil }(\%)=\frac{(\mathrm{ml} \text { blangko }-\mathrm{ml} \text { sampel }) \times \mathrm{N} \text { asam } \times 0,028 \times 100}{\text { berat pati }(\text { dry basis })}
$$

Kadar karboksil ditentukan dengan metode ISO 11214 (1996). $5 \mathrm{~g}$ sampel ditambah $25 \mathrm{ml} \mathrm{HCl} \mathrm{0,1} \mathrm{N,} \mathrm{kemudian} \mathrm{diaduk}$ 30 menit dengan magnetic stirer. Slury kemudian disaring dengan pembilasan menggunakan $300 \mathrm{ml}$ aquades. Pati yang tertinggal ditambahkan $300 \mathrm{ml}$ aquades, kemudian di panaskan pada suhu $100{ }^{\circ} \mathrm{C}$ ( 15 menit). Sampel lalu dititrasi dengan $\mathrm{NaOH} 0,1$ $\mathrm{N}$ hingga $\mathrm{pH}$ mencapai 8,3 dengan pati sagu alami digunakan sebagai blangko.

$$
\text { kadar karboksil }(\%)=\frac{(\mathrm{ml} \text { sampel }- \text { ml blangko }) \times \mathrm{N} \mathrm{NaOH} \mathrm{x} \mathrm{0,045} \mathrm{x} 100}{\text { berat pati }(\text { dry basis })}
$$

Karakteristik amilografi tepung ditentukan dengan menggunakan Brabender Viscoamylograph, dengan kondisi larutan tepung $(7 \%)$ dipanaskan pada suhu $30-90$ ${ }^{\circ} \mathrm{C}$, dengan laju peningkatan suhu 1,5 ${ }^{\circ} \mathrm{C} / \mathrm{menit}$. Selanjutnya suhu dipertahankan pada $90{ }^{\circ} \mathrm{C}$ selama 20 menit kemudian sampel didinginkan hingga suhu $50{ }^{\circ} \mathrm{C}$ dengan laju pendinginan $1.5^{\circ} \mathrm{C} /$ menit.

\section{Penentuan Sifat Baking Expansion Pati Sagu}

Baking expansion pati sagu ditentukan menggunakan metode Demiate et al. (2000), dengan sedikit modifikasi. Sebanyak 24 gram pati ditambah $30 \mathrm{ml}$ aquades, lalu digelatinisasikan. Adonan dibagi rata menjadi 3 bagian, lalu dioven pada suhu $200^{\circ} \mathrm{C}$ selama 25 menit. Hasil panggangan kemudian didinginkan, ditimbang, kemudian dilapisi 
permukaannya dengan pencelupan dalam parafin. Volume hasil panggangan ditentukan dengan mencelupkan sampel dalam gelas ukur berisi air, hingga seluruh bagian terendam, dan peningkatan volume tercatat. Sifat baking expansion dinyatakan dalam volume spesifik, dengan membagi volume dengan massa hasil panggangan $(\mathrm{ml} / \mathrm{g})$.

\section{HASIL DAN PEMBAHASAN}

\section{Pengaruh fotooksidasi UV C terhadap derajat putih pati sagu}

Pengaruh fotooksidasi terhadap derajat putih pati sagu dapat dilihat pada Tabel 1 . Adapun pengukuran derajat putih dilakukan menggunakan chromameter Minolta CR-400 dan diperoleh nilai $\mathrm{L}$ dari masing-masing perlakuan. Oksidasi pati menggunakan oksidator kimia dilaporkan dapat meningkatkan derajat putih tapioka (Dewi, 2011; Tetelepta, 2011).

Tabel 1. Warna Pati

\begin{tabular}{lc}
\hline \multicolumn{1}{c}{ Perlakuan } & Derajat Putih \\
\hline Pati alami & $92,05^{\mathrm{e}}$ \\
Rasio $1: 2$ & $89,11^{\mathrm{d}}$ \\
Rasio $1: 4$ & $88,72^{\mathrm{c}}$ \\
Rasio $1: 6$ & $88,39^{\mathrm{c}}$ \\
Rasio $1: 8$ & $87,04^{\mathrm{b}}$ \\
Rasio $1: 10$ & $86,35^{\mathrm{a}}$ \\
\hline
\end{tabular}

Ket: Huruf yang berbeda pada kolom yang sama menunjukkan perbedaan pada taraf $95 \%$

Namun, perlakuan pemaparan dengan UV dapat menurunkan derajat putih pati sagu. Dari Tabel 1, derajat putih pati sagu alami sebesar 92,05 sedangkan nilai derajat putih pati sagu oksidasi 86,35-89,11. Hal ini diduga karena adanya kandungan enzim fenolase pada pati sagu (Miftahorrachman dan Novarianto, 2003). Dimana ketika pati dipaparkan sinar UV, akan memicu oksidasi enzim fenolase yang terdapat pada pati sagu sehingga menyebabkan pencoklatan enzimatis (Winarno, 1997). Berdasarkan Tabel 1, derajat putih pati sagu oksidasi menurun seiring dengan makin encernya slurry pati. Pada rasio pati : air sebesar 1:2, derajat putih pati sagu oksidasi sebesar 89,11, sedangkan nilai derajat putih terendah diperoleh dari perlakuan rasio pati : air 1:10 dengan nilai $\mathrm{L}$ sebesar 86,35. Hal ini kemungkinan disebabkan karena makin sedikit partikel pati dalam slurry pati, maka paparan sinar UV makin intensif sehingga enzim fenolase pada pati sagu akan teroksidasi menghasilkan warna pati yang lebih gelap.

\section{Pengaruh fotooksidasi UV C terhadap sifat fisikokimia pati sagu}

Reaksi oksidasi menyebabkan terjadinya perubahan sifat fisikokimia pati. Karakteristik fisikokimia pati sagu setelah fotooksidasi UV C ditampilkan pada Tabel 2. Makin sedikit partikel pati dalam slurry kadar amilosa pati meningkat. Hal ini disebabkan karena terjadinya depolimerisasi molekul amilopektin yang menghasilkan potongan rantai pendek yang linear, sehingga ketika direaksikan dengan larutan iod kadar amilosa akan tampak meningkat (Kuakpetoon and Wang, 2006).

Tabel 2 juga menunjukkan daya pengembangan dan kelarutan pati sagu teroksidasi lebih rendah dibanding pati sagu alami. Akibat reaksi oksidasi yang lemah memicu pembentukan hemiketal dan hemiacetal pada molekul pati dan adanya penyinaran dengan UV-C akan memicu photocrosslinking pada molekul pati (Lorlowhakarn and Naivikul, 2005). Oksidasi menyebabkan struktur granula menjadi lebih porus sehingga kemampuan menghidrasi air pada saat pemanasan tinggi, namun saat sentrifugasi air terabsorb akan keluar karena ketahanan granula dalam memerangkap air lemah (Wang and Wang, 2003) sehingga daya pengembangan pati menurun. Sementara kelarutan menurun karena adanya crosslinking dapat menghambat larutnya fraksi amilosa.

Selama proses oksidasi gugus hidroksil pada molekul pati teroksidasi menjadi gugus karbonil kemudian menjadi gugus karboksil (El-sheikh et al._2010; Kuakpetoon and Wang, 2006). Namun, meningkatnya rasio slurry menurunkan kadar karbonil dan karboksil dari pati teroksidasi UV C. Hal ini kemungkinan disebabkan oksidasi yang terjadi kurang intensif sehingga kadar karbonil dan karboksil yang dihasilkan lebih rendah, karena jumlah partikel pati dalam slurry lebih sedikit sehingga pergerakan partikel akan lebih cepat dan kontak dengan oksidator berkurang. Pergerakan partikel yang makin cepat dengan makin sedikitnya jumlah partikel pati dalam 
slurry akan cenderung membentuk pergerakan sesuai dengan Teori Gerak Brown yang menyatakan bahwa partikel tidak pernah dalam keadaan stasioner dan jika diamati dengan mikroskop tampak membentuk gerakan zig-zag.

Tabel 2. Karakteristik Fisikokimia Pati Sagu

\begin{tabular}{lccccc}
\hline Perlakuan & $\begin{array}{c}\text { Kadar } \\
\text { amilosa } \\
(\%) b k)\end{array}$ & $\begin{array}{c}\text { Daya } \\
\text { Pengembangan } \\
(\% \mathbf{\% k})\end{array}$ & $\begin{array}{c}\text { Kelarutan } \\
(\% \mathbf{\% k})\end{array}$ & $\begin{array}{c}\text { Kadar } \\
\text { Karbonil } \\
(\% \mathbf{\% k})\end{array}$ & $\begin{array}{c}\text { Kadar } \\
\text { Karboksil } \\
(\% \mathbf{\% k})\end{array}$ \\
\hline Pati alami & $31,87^{\mathrm{a}}$ & $38,10^{\mathrm{d}}$ & $25,29^{\mathrm{d}}$ & $0,45^{\mathrm{d}}$ & $0,33^{\mathrm{d}}$ \\
Rasio $1: 2$ & $31,95^{\mathrm{a}}$ & $37,65^{\mathrm{c}}$ & $24,04^{\mathrm{c}}$ & $0,39^{\mathrm{c}}$ & $0,25^{\mathrm{c}}$ \\
Rasio $1: 4$ & $32,17^{\mathrm{b}}$ & $37,41^{\mathrm{c}}$ & $23,86^{\mathrm{b}}$ & $0,23^{\mathrm{b}}$ & $0,24^{\mathrm{c}}$ \\
Rasio $1: 6$ & $32,48^{\mathrm{b}}$ & $36,72^{\mathrm{b}}$ & $23,73^{\mathrm{b}}$ & $0,13^{\mathrm{a}}$ & $0,19^{\mathrm{b}}$ \\
Rasio $1: 8$ & $33,11^{\mathrm{c}}$ & $36,57^{\mathrm{b}}$ & $23,26^{\mathrm{a}}$ & $0,12^{\mathrm{a}}$ & $0,15^{\mathrm{a}}$ \\
Rasio $1: 10$ & $33,13^{\mathrm{c}}$ & $35,61^{\mathrm{a}}$ & $23,31^{\mathrm{a}}$ & $0,12^{\mathrm{a}}$ & $0,13^{\mathrm{a}}$ \\
\hline
\end{tabular}

Ket: Huruf yang berbeda pada kolom yang sama menunjukkan perbedaan pada taraf $95 \%$

Pengaruh fotooksidasi UV C terhadap sifat amilografi pati sagu

Sifat amilografi pati sagu pada beberapa rasio slury fotooksidasi UV-C ditampilkan pada Tabel 3. Tabel 3 menunjukkan bahwa viskositas pasta pati oksidasi lebih tinggi daripada viskositas puncak pasta pati alami.

Tabel 3. Sifat Amilografi Pati Sagu Teroksidasi UV-C

\begin{tabular}{|c|c|c|c|c|c|c|}
\hline \multirow[b]{2}{*}{ Perlakuan } & \multicolumn{2}{|c|}{ Gelatinisasi } & \multicolumn{3}{|c|}{ Viscositas Puncak } & \multirow{2}{*}{$\begin{array}{c}\text { Viscositas dingin } \\
50^{\circ} \mathrm{C}(\mathrm{cP})\end{array}$} \\
\hline & $\begin{array}{l}\text { Waktu } \\
\text { (menit) }\end{array}$ & $\begin{array}{c}\text { Suhu } \\
\left({ }^{\circ} \mathrm{C}\right)\end{array}$ & $\begin{array}{l}\text { Waktu } \\
\text { (menit) }\end{array}$ & $\begin{array}{c}\text { Suhu } \\
\left({ }^{\circ} \mathrm{C}\right)\end{array}$ & $\begin{array}{c}\text { Viscositas } \\
\text { (cP) }\end{array}$ & \\
\hline Pati alami & 14 & 73,2 & 21 & 92,6 & 352,0 & 326,4 \\
\hline Rasio 1:2 & 12 & 68,0 & 19 & 90,6 & 601,6 & 684,8 \\
\hline Rasio 1:4 & 12 & 68,1 & 19 & 90,7 & 1056,0 & 1152,0 \\
\hline Rasio 1:6 & 11 & 69,3 & 17 & 91,0 & 1664,0 & 1785,6 \\
\hline Rasio 1:8 & 11 & 67,7 & 17 & 89,4 & 2764,8 & 2700,8 \\
\hline Rasio 1:10 & 12 & 69,4 & 18 & 89,7 & 3404,8 & 3180,8 \\
\hline
\end{tabular}

Peningkatan viskositas pasta pati oksidasi diduga karena terjadi slight oxidation (oksidasi ringan) sehingga membentuk hemiketal atau hemiasetal crosslink yang diasumsikan terjadi di antara molekul amilopektin dan kemungkinan kecil berada di antara molekul amilosa dan amilopektin (Kuakpetoon and Wang, 2006). Gugus aldehid yang terbentuk pertama kali pada level oxidan yang rendah membentuk hemiasetal crosslink sehingga terjadi peningkatan berat molekul yang menyebabkan viskositas makin tinggi (Wang and Wang, 2003). Kurva amilografi pati sagu pada beberapa rasio slurry dapat dilihat pada
Gambar 2. Rasio pati:air berpengaruh terhadap viskositas pasta. Makin sedikit partikel pati dalam slurry pati maka viskositas pasta makin tinggi. Hal ini disebabkan karena makin sedikit partikel pati dalam slurry pati maka reaksi oksidasi yang terjadi kurang intensif.

\section{Pengaruh fotooksidasi UV C terhadap sifat baking expansion pati sagu}

Hasil analisis baking expansion pati sagu ditampilkan pada Tabel 4. Tabel 4 menunjukkan bahwa fotooksidasi dengan UV $\mathrm{C}$ meningkatkan volume spesifik atau sifat baking expansion pati sagu. 
AGROINTEK Volume 11, No. 2 Agustus 2017

Tabel 4. Baking Expansion pati sagu

\begin{tabular}{ccc}
\hline Perlakuan & Baking Expansion $(\mathbf{m L} / \mathbf{g})$ & Persen Pengembangan (\%) \\
\hline Pati alami & $5,22 \pm 0,0354^{\mathrm{a}}$ & - \\
Rasio $1: 2$ & $6,37 \pm 0,0283^{\mathrm{d}}$ & 22,1 \\
Rasio $1: 4$ & $6,19 \pm 0,0495^{\mathrm{c}}$ & 18,6 \\
Rasio $1: 6$ & $6,97 \pm 0,0283^{\mathrm{f}}$ & 33,7 \\
Rasio $1: 8$ & $6,81 \pm 0,0141^{\mathrm{e}}$ & 30,6 \\
Rasio $1: 10$ & $5,81 \pm 0,0778^{\mathrm{b}}$ & 11,3 \\
\hline
\end{tabular}

Ket: Huruf yang berbeda pada kolom yang sama menunjukkan perbedaan pada taraf $95 \%$

Volume pengembangan terendah pengembangan tertinggi dihasilkan pati dari dihasilkan dari rasio campuran pati:air adalah rasio campuran 1:6, yaitu sebesar 6,97 ml/g; 1:10, dimana volume spesifiknya sebesar 5,81 atau meningkat $33,7 \%$ dibandingkan pati $\mathrm{ml} / \mathrm{g}$; atau meningkat $11,3 \%$ dibandingkan alami. Hasil baking expansion pati dari pati alami yang tidak dilewatkan pada alat beberapa rasio slury ditampilkan pada fotooksidator UV. Sedangkan volume Gambar 2.
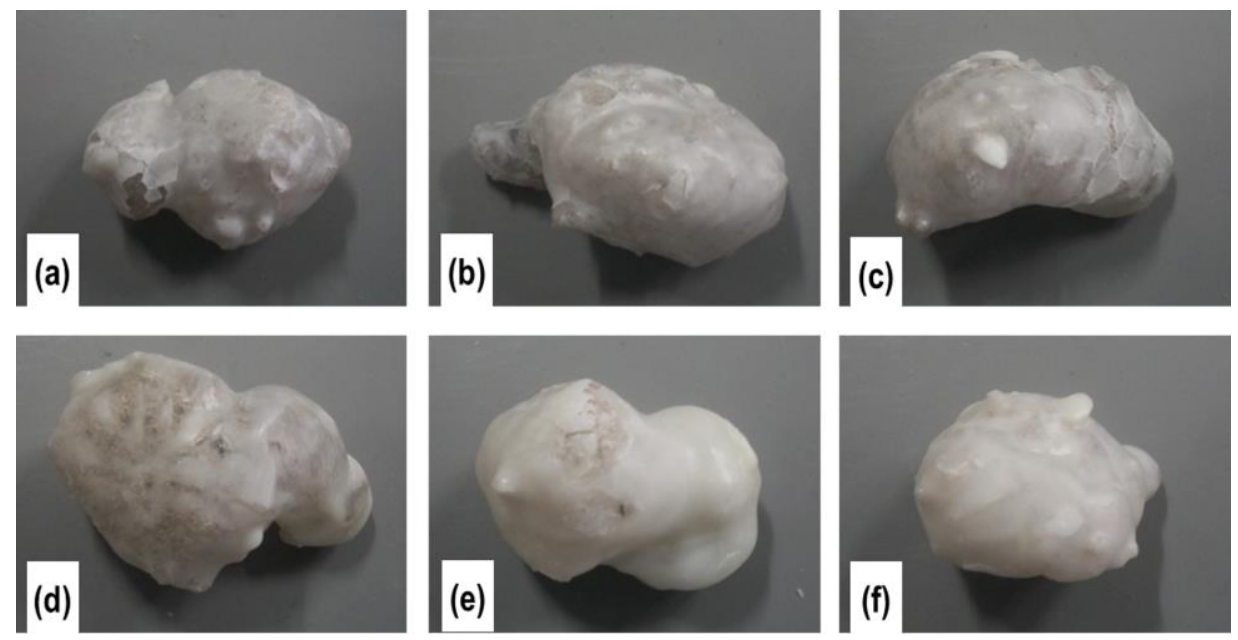

Gambar 2 Hasil baking pati sagu, (a) pati alami; (b) rasio slurry 1:2; (c) rasio slurry 1:4; (d) rasio slurry 1:6; (e) rasio slurry 1:8; (f) rasio slurry 1:10

Peningkatkan nilai baking expansion pati sagu teroksidasi disebabkan karena proses oksidasi pati menyebabkan jumlah air yang terikat dalam pati semakin banyak, sehingga uap air selama proses baking makin banyak pula dan pengembangan produk menjadi semakin besar (Bertolini et al. 2001). Sementara penurunan volume baking pada rasio slurry tinggi disebabkan karena fotooksidasi berlebih menyebabkan degradasi pati pada dinding bahan terlalu ekstensif sehingga kehilangan integritasnya lebih awal dan tidak terjadi pengembangan (Vatanasuchart et al., 2005).

\section{KESIMPULAN}

Peningkatan derajat oksidasi dengan peningkatan rasio slurry akan meningkatkan kadar amilosa dan sebaliknya menurunkan daya pengembangan dan kelarutan, serta kadar karbonil dan karboksil dari pati teroksidasi. Penggunaan UV $\mathrm{C}$ sebagai fotooksidator pati sagu efektif meningkatkan daya pengembangan pati, dengan rasio slurry (pati:air) terbaik untuk digunakan pada proses fotooksidasi adalah rasio 1 : 6, dimana menghasilkan volume spesifik pati pada saat pemanggangan sebesar $6,97 \mathrm{ml} / \mathrm{g}$ atau 
meningkat sebesar 33,7 \% dibandingkan pati alami $(5,22 \mathrm{ml} / \mathrm{g})$.

\section{DAFTAR PUSTAKA}

Adebowale, K.O., Afolabi, T.A., Lawal, O.S. 2002. Isolation, chemical modification and physicochemical characterisation of Bambarra groundnut (Voandzeia subterranean) starch and flour. Food Chemistry 78:305-311. doi: 10.1016/S0308-8146(02)00100-0

M.M. Sanchez-Rivera, F.J.L. Garcia Suarez, M. Velazquez del Valle. F. GutierrezMeraz, L.A. Bello Perez. 2005. Partial Characterization of Banana Starches Oxidized by Different Levels of Sodium Hypochlorite. Carbohydrate Polymers 62:50-56. doi: 10.1016/j.carbpol.2005.07.005

Bertolini, A.C., Mestres, C., Lourdin, D., del Valle, G., Colonna, P. 2001. Relationship between thermomechanical properties and baking expansion of sour cassava starch (Polvilho Azedo). Journal of the Science of Food and Agriculture 81: 429-435. doi : 10.1002/10970010(200103)81:4<429: $\quad$ AIDJSFA833>3.0.CO;2-2.

Demiate, I.M., Dupuy, N., Huvenne, J.P., Cereda, M.P., Wosiacki, G. 2000. Relationship between baking behavior of modified cassava starches and starch chemical structure determined by FTIR spectroscopy. Carbohydrate Polymers 42: 149-158. doi: 10.1016/S01448617(99)00152-6

Dewi, A. M. P., 2011. Oksidasi Tapioka Dengan Hidrogen Peroksida dan Katalisis UV-C, Serta Aplikasinya Untuk Edible Film. [Tesis]. Yogyakarta : Universitas Gadjah Mada.

El-sheikh, M. A., Ramadan, M. A., El-shafie, A. 2010. Photo-oxidation of rice starch. Part I: Using hydrogen peroxide. Carbohydrate Polymers 80:266-269. doi: 10.1016/j.carbpol.2009.11.023

Flach, M. 1997. Sago Palm. Metroxylon Sagu Rottb. International Plant Genetic Resources Institute (IPGRI). Rome, Italy.
Haryanto, B. dan P. Pangloli. 1991. Potensi dan Pemanfaatan Sagu. Kanisius: Yogyakarta

Kuakpetoon, D., and Wang, Y.J. 2006. Structural characteristics and physicochemical properties of oxidized corn starches varying in amylose content. Carbohydrate Research 341:1896-1915. doi: 10.1016/j.carres.2006.04.013.

Limbongan, J. 2007. Morfologi Beberapa Jenis Sagu Potensial di Papua. Jurnal Penelitian dan Pengembangan Pertanian. 26 (1).

Lorlowhakarn, K., and O. Naivikul. 2005. Modification of Rice Flour by UV Irradiation to Improve Rice Noodle Quality. Proceeding of The 3th Conference of Starch Technology: Thailand.

Miftahorrachman dan H. Novarianto. 2003. Jenis-jenis sagu potensial di Sentani Irian Jaya. Prosiding Seminar Nasional Sagu: Manado, 6 Oktober 2003.

Smith, R. J. 1896. Production and used of hypochlorite oxidized starches (Vol. II). Di dalam R. L. Whistler, \& E. F. Paschall (ed.), Starch chemistry and technology. New York: Academic Press. P620-625.

Tetelepta, G. 2011. Oksidasi pati tapioca dengan sodium hipoklorit guna meningkatkan baking expansion. [Tesis] Yogyakarta: Universitas Gadjah Mada

Tethool, E.F., Z. L. Sarungalo, B. Santoso. 2009. Sifat Fisikokimia dan Daya Cerna Empat Kultivar Pati Sagu Asal Sentani Papua. Indofood Riset Nugraha 2008. Manokwari : Universitas Negeri Papua.

Vatanasuchart, N., Naivikul, O., Charoenrein, S., Sriroth, K. 2005. Molecular Properties of Cassava Starch Modified With Different UV Irradiation to Enhance Baking Expansion. Carbohydrate Polymers 61: 80-87, doi $: 10.1016 / j . c a r b p o l .2005 .02 .012$ 
AGROINTEK Volume 11, No. 2 Agustus 2017

Wang, Y.J., and Wang, L. 2003. Physicochemical properties of common and waxy corn starch oxidized by different level of sodium hypochlorite. Carbohydrate Polymers 52 : 207-217, doi: 10.1016/S0144-8617(02)003041

Winarno, F. G. 1997. Kimia Pangan dan Gizi.

PT. Gramedia : Jakarta 